\title{
Precision Medicine with Genetic Testing in Neonatal Intensive care
}

\author{
Vishnu Anand ${ }^{1}$ Femitha Pournami ${ }^{1}$ (1) Anand Nandakumar ${ }^{1}$ Jyothi Prabhakar ${ }^{1}$ Naveen Jain ${ }^{1}$ \\ ${ }^{1}$ Department of Neonatology, Kerala Institute of Medical Sciences, \\ Trivandrum, Kerala, India \\ Address for correspondence Femitha Pournami, DM, Department of \\ Neonatology, Kerala Institute of Medical Sciences, Trivandrum \\ 695029, Kerala, India (e-mail: femi_shifas@yahoo.com).
}

J Child Sci 2021;11:e216-e217.

The highest impact of genetic disorders through a human being's lifespan is during fetal, perinatal, and neonatal periods. Accurate diagnosis optimizes management decisions, and aids parent counseling. Medical professionals in the field must therefore be cognizant of the foundations of genetic diseases and the indications, choices, prerequisites, and benefits of selection of appropriate tests. Inappropriate selection of tests comes with several downsides-in the form of costs, inconclusive results, and ethical dilemmas. This article seeks to demystify succinctly, from a clinician's perspective, the various genetic tests available and aid selection of the most appropriate one in a given situation.

We recently reported our experience with genetic tests conducted in our unit over the past 5 years. ${ }^{1}$ In our unit, specific testing is offered to all families whose babies present with the likelihood of a genetic diagnosis. More than $80 \%$ of them accepted the test after detailed discussions with a qualified senior genetic counselor. Cost did not seem to be a major determinant of decision making. Of 61 tests done in 57 neonates in our unit, in $66.7 \%$ of patients, the test results had strong clinical utility. Farnaes et al reported that diagnostic sensitivity of rapid whole genome sequencing (rWGS) was $43 \%$ (18 of 42 infants) and 10\% (4 of 42 infants) for standard genetic tests $(p=0.0005){ }^{2}$ In a highly selective group of neonatal intensive care unit admissions, a genetic diagnosis was obtained in $57 \%$ of patients with rWGS. ${ }^{3}$ The recent NSIGHT study which planned to study proportion of sick infants who received a diagnosis with rWGS was terminated early, as among infants enrolled in the first 25 days of life, the rate of neonatal diagnosis was high in cases where advanced tests were done (32\%, 7 of 22$){ }^{4}$

An exhaustive history taking, pedigree charting followed by interdisciplinary clinical evaluation, is imperative. The expertise of clinical geneticists alongside software-based algorithms may help in selection of appropriate tests. Professional counseling of the family is the key to shared and optimal

decision making. A trained genetic counselor has in-depth scientific knowledge as well as effective communication skills. As part of pretest counseling, possible uncertainties due to present gaps in knowledge are also discussed.

Choosing the correct test requires basic knowhow about each one (-Table 1 and $\boldsymbol{- F i g . ~} \mathbf{1}$ ). Disorders of chromosome number, imbalances of insertion, and translocation are usually detected by karyotyping. As this testing method requires cells in the dividing state, turnaround time becomes a limiting factor. Fluorescence in situ hybridization is faster, and can detect aneuploidy, balanced and unbalanced translocations, microdeletions, and duplications that conform to the resolution of the microscope. Chromosomal microarray (CMA) is primarily used to detect copy number variations. High sensitivity of testing detects submicroscopic genetic imbalances. Guidelines now recommend CMA as part of firsttier testing in situations of congenital malformations and global developmental delays. In circumstances where singlegene mutation disorders are suspected clinically, the technique most commonly employed is Sanger sequencing, which can detect mutations that affect coding sequences. This method is labor-intensive and time-consuming. Nextgeneration clinical exome sequencing involves analysis of all protein-coding sequences in the human genome. The massive parallel strategy is used enabling rapid genome-scale sequencing of DNA at a significantly reduced cost relative to the Sanger method. Genomic DNA from a patient is isolated, fragmented into tiny segments, coupled to artificial linkers, and sequenced in parallel. These are assembled as a series of overlapping fragments and aligned to a reference. "Variants" may be benign polymorphisms or pathogenic mutations. There may be differences between laboratories in completeness of gene coverage, how the reports are validated, and the methods used to interpret variants.

The term variant of uncertain significance (VUS) refers to a change in a gene of interest that is novel or rare in the

received

April 21, 2021

accepted after revision

June 14, 2021
DOI https://doi.org/

$10.1055 / \mathrm{s}-0041-1733875$.

ISSN 2474-5871. (c) 2021. The Author(s).

This is an open access article published by Thieme under the terms of the Creative Commons Attribution License, permitting unrestricted use, distribution, and reproduction so long as the original work is properly cited. (https://creativecommons.org/licenses/by/4.0/)

Georg Thieme Verlag KG, Rüdigerstraße 14, 70469 Stuttgart, Germany 
Table 1 Classification of genetic tests from clinician perspective

\begin{tabular}{|l|l|l|}
\hline SI. No. & Genetic basis of suspected disease or condition & Genetic test \\
\hline 1 & $\begin{array}{l}\text { Disorders of chromosomal number (aneuploidy) } \\
\text { Gross structural variations (insertions, translocations, arm } \\
\text { deletions, ring chromosomes) }\end{array}$ & KT (needs dividing cells) \\
\hline 2 & $\begin{array}{l}\text { Aneuploidies; microdeletion/duplication syndromes; } \\
\text { copy number variations }\end{array}$ & $\begin{array}{l}\text { FISH (faster than KT and CMA, but for known } \\
\text { microdeletions only); ideal-CMA; MLPA }\end{array}$ \\
\hline 3 & $\begin{array}{l}\text { Single-gene disorders with phenotype that can narrow the } \\
\text { diagnostic spectrum to a specific disease }\end{array}$ & NGS panels \\
\hline 4 & $\begin{array}{l}\text { Copy number changes of small DNA fragments or exonic } \\
\text { deletions }\end{array}$ & MLPA \\
\hline 5 & $\begin{array}{l}\text { Confirmation of NGS in parents and/or other affected family } \\
\text { members }\end{array}$ & Sanger sequencing \\
\hline 6 & Suspected trinucleotide repeat disorders & PCR \\
\hline 7 & $\begin{array}{l}\text { Suspected intron region disorder in the differential } \\
\text { diagnosis }\end{array}$ & Whole genome sequencing \\
\hline
\end{tabular}

Abbreviations: CMA, chromosomal microarray; FISH, fluorescence in situ hybridization; KT, karyotyping; MLPA, multiplex ligation dependent probe amplification; NGS, next generation sequencing; PCR, polymerase chain reaction.

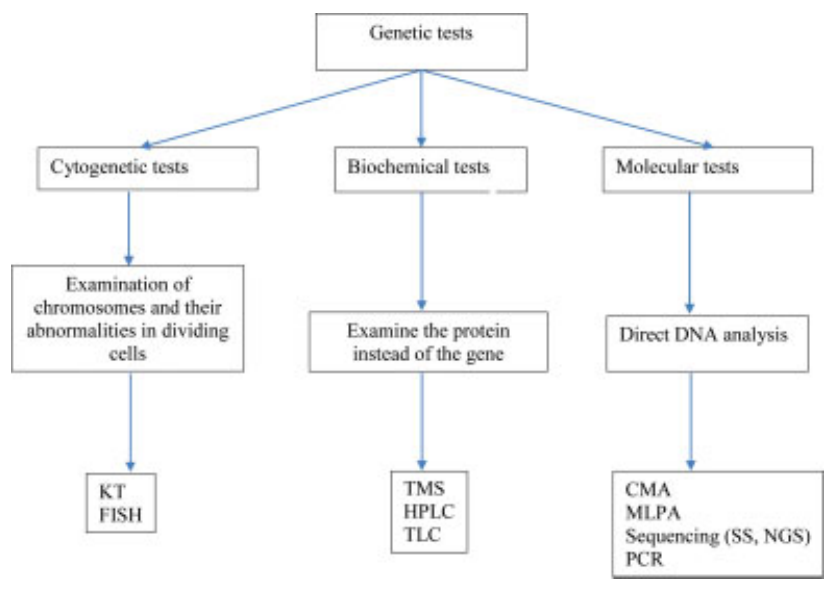

Fig. 1 Types of genetic tests. CMA, chromosomal microarray; FISH, fluorescence in situ hybridization; HPLC, high performance liquid chromatography; KT, karyotyping; MLPA, multiplex ligation dependent probe amplification; NGS, next generation sequencing; PCR, polymerase chain reaction; TLC, thin layer chromatography; TMS, tandem mass spectroscopy.

population and has never been reported in connection with disease. ${ }^{5}$ Bioinformatic prediction methods are used to classify VUS. These variants may be reclassified when new information is available in the scientific literature. False negatives may arise as a small proportion of disease can result from mutations in deep intronic regions that regulate and promote gene expression (exome makes up only $1.5 \%$ of the whole human genome). Whole genome studies sequence the complete DNA of an organism.

The evolving field of molecular pathological epidemiology (MPE) is an integrative one that analyses the interplay between exposures that are endogenous and exogenous. ${ }^{6}$ Lifestyle, diet, microbiome, and environmental factors can influence intrinsic genetic make-up.

To conclude, results of genetic tests made significant impact on clinical management of several cases in our experience. Genetic testing seems to have a cogent role in management of sick neonates whose phenotype and clinical course warrant work-up for genetic disorders. Appropriate patient selection, pretest counseling, correct choice of test, and quality control steps in laboratory processes would ensure accuracy of results and improve clinical impact. Precision medicine in the future will gain from advances in MPE research as well, toward tailored preventive and treatment decisions.

\section{Funding \\ None.}

\section{Conflict of interest}

None declared.

\section{References}

1 Anand V, Pournami F, Madhavilatha GK, Prabhakar J, Nandakumar A, Jain N. Genetic testing in neonatal intensive care: experience from a tertiary care unit. Indian J Pediatr 2021;88(04):398-399

2 Farnaes L, Hildreth A, Sweeney NM, et al. Rapid whole-genome sequencing decreases infant morbidity and cost of hospitalization. NPJ Genom Med 2018;3:10

3 Willig LK, Petrikin JE, Smith LD, et al. Whole-genome sequencing for identification of Mendelian disorders in critically ill infants: a retrospective analysis of diagnostic and clinical findings. Lancet Respir Med 2015;3(05):377-387

4 Petrikin JE, Cakici JA, Clark MM, et al. The NSIGHT1-randomized controlled trial: rapid whole-genome sequencing for accelerated etiologic diagnosis in critically ill infants. NPJ Genom Med 2018;3:6

5 Oulas A, Minadakis G, Zachariou M, Spyrou GM. Selecting variants of unknown significance through network-based gene-association significantly improves risk prediction for disease-control cohorts. Sci Rep 2019;9(01):3266

6 Hamada T, Nowak JA, Milner DA Jr, Song M, Ogino S. Integration of microbiology, molecular pathology, and epidemiology: a new paradigm to explore the pathogenesis of microbiome-driven neoplasms. J Pathol 2019;247(05):615-628 